\title{
Potent Inhibitory Effects of Transplantable Rat Glucagonomas and Insulinomas on the Respective Endogenous Islet Cells Are Associated with Pancreatic Apoptosis
}

\author{
Niels Blume, ${ }^{*}$ Jan Skouv, ${ }^{\star}$ Lars-Inge Larsson, ${ }^{\ddagger}$ Jens J. Holst, ${ }^{\S}$ and Ole D. Madsen ${ }^{\star}$ \\ ${ }^{*}$ Hagedorn Research Institute, 2820 Gentofte, Denmark; ${ }^{\ddagger}$ Department of Molecular Cell Biology, State Serum Institute, 2300 \\ Copenhagen S, Denmark; and ${ }^{\S}$ Department of Medical Physiology, The Panum Institute, University of Copenhagen, 2200 Copenhagen \\ $N$, Denmark
}

\begin{abstract}
Effects of transplantable rat insulinomas (IN) and glucagonomas (GLU) on the endogenous pancreas were analyzed using morphometry, immunocytochemistry, in situ hybridization, and staining for apoptotic cells. Hyperinsulinemia (IN-rats) and hyper-GLP-1/glucagonemia (GLU-rats) were both associated with marked islet atrophy ( 67 and $76 \%$ of control average planimetrical islet area, respectively). Selective islet $B$ cell inhibition of proinsulin (I and II) genes as well as of expression of the insulin gene transcription factor, IPF1/STF1, was found in IN-rats. Moreover, these islets were characterized by significant $B$ cells apoptosis in the absence of infiltrating lymphocytes. In GLU-rats selective islet $A$ cell inhibition was observed at the level of glucagon mRNA. These islets contained small, highly condensed but clearly active B cells with prominent IPF1/STF1-positive nuclei, surrounded by densely packed glucagon-negative cells with reduced cytoplasm. Furthermore, an active apoptotic process was found exclusively in the exocrine pancreas of GLU-rats. Thus, in IN-rats, islet B cell mass reduction is distinguished by non-immune-mediated programmed cell death, while GLU-rats exhibit A cell mass reduction by cytoplasmic retraction and selective exocrine apoptosis. (J. Clin. Invest. 1995. 96:2227-2235.) Key words: glucagonoma • insulinoma • gene expression • pancreatic B cell $\cdot$ apoptosis
\end{abstract}

\section{Introduction}

It has been well documented that transplantable glucagonomas $(\mathrm{GLU})^{1}(1,2)$ or insulinomas (IN) $(3-6)$ in rodents selectively cause downregulation of the respective endogenous islet hormones, suggesting the existence of a negative "feedback mechanism" from the transplanted islet tumor phenotype to the corre-

Address correspondence to Ole D. Madsen, Hagedorn Research Institute, Niels Steensensvej 6, DK-2820 Gentofte, Denmark. Phone: 4531680860; FAX: 45-44438000; E-mail: odm@hrl.dk

Received for publication 25 April 1995 and accepted in revised form 31 July 1995.

1. Abbreviations used in this paper: GLU, glucagonoma; IN, insulinoma; IPF1, insulin promoter factor 1; STF1, somatostatin transcription factor 1 (the rat homologue of mouse IPF1).

J. Clin. Invest.

(C) The American Society for Clinical Investigation, Inc.

0021-9738/95/11/2227/09 \$2.00

Volume 96, November 1995, 2227-2235 sponding islet cell. Additionally, islet size is reduced in these tumor-bearing animals, which has been explained by the selective atrophy of the respective islet cell type.

We have reported previously the establishment of stable transplantable rat insulinomas (MSL-G2-IN) (7) and glucagonomas (MSL-G-AN) (8) from common clonal origin. The B cell tumor MSL-G2-IN causes a classical syndrome of hypoglycemia due to hyperinsulinemia. The MSL-G-AN glucagonoma has a mixed pancreatic $A$ and intestinal $L$ cell phenotype with respect to posttranslational proglucagon processing. Thus, glucagon and glucagon-like peptide-1 7-36 amide [GLP-1 (7-36 amide)] are the main secretory products; however, glicentinrelated polypeptide, oxyntomodulin, GLP-2, as well as other processing variants of GLP-1 are secreted also (8). The MSLG-AN tumor line causes an abrupt onset of severe anorexia and adipsia 4-5 wk after transplantation (9), the nature of which remains unsolved. Despite hyperglucagonemia, other murine glucagonomas are not associated with severe anorexia $(1,2)$, although a prominent weight loss may be seen in the glucagonoma syndrome in humans (10). In addition, several reports have been demonstrating a minor, but direct, postprandial satiety effect of glucagon treatment $(11-15)$.

The nature of tissue-specific expression and regulation of insulin and glucagon genes has been studied extensively during the past few years and involves complex interactions between cis elements in the gene promoters and combinations of ubiquitous and cell-specific transactivating factors $(16,17)$. Of particular interest is the recently cloned transcription factor, insulin promoter factor 1 /somatostatin transcription factor 1 (IPF1/ STF1 $)(18,19)$, which has been shown to be essential for both pancreatic formation during ontogeny $(20)$ as well as for insulin gene transcription in the mature B cell (21-23). The mechanisms by which glucagonomas and insulinomas inhibit $\mathrm{A}$ and B cell function in islets of Langerhans are not well established.

The aim of this study was to characterize specific effects on the endocrine pancreas in syngeneic rats by transplantation of the highly distinct phenotypes of the glucagonoma (MSL-GAN) and insulinoma (MSL-G2-IN). Expression of the principal hormones of the endogenous A and B cells was analyzed at the protein and mRNA levels. Additionally, expression of the transcription factor, IPF1/STF1, was analyzed by immunocytochemistry. Finally, we analyzed both the pancreatic exocrine and endocrine compartments for atrophy using morphometry and for the presence of apoptosis.

\section{Methods}

Animals. Inbred New England Deaconess Hospital (NEDH) albino rats were housed with free access to food and water. Controls and rats transplanted with MSL-G-AN glucagonomas or MSL-G2-IN insulino- 
mas subcutaneously in the neck as described previously (8) were included in this study ( $n=6-8$, for each group). Sucrose ( $10 \% \mathrm{wt} / \mathrm{vol})$ was added to the drinking water $1 \mathrm{wk}$ after transplantation for rats receiving insulinoma tissue in order to prevent acute hypoglycemia. The MSL-G-AN glucagonoma-transplanted rats were killed 3-4 wk after transplantation when they had lost $\sim 30 \%$ of their maximum weight. MSL-G2-IN-transplanted rats were killed 6-8 wk after transplantation when their blood glucose levels were below $2.5 \mathrm{mM}$. The animals were anesthetized with pentobarbital sodium $(50 \mathrm{mg} / \mathrm{kg}$ body wt, intraperitoneally), and blood samples were obtained by cardiac puncture for endpoint measurements of plasma levels of circulating insulin, glucagon, and GLP-1. Animals were handled according to permission obtained from the Committee for Inspection of Animal Experiments under the Danish Ministry of Justice.

Radioimmunoassay. Glucagon and GLP-1 were measured by radioimmunoassay using processing independent assays. For glucagon assays antibody 4304, directed against the 6-15 sequence of glucagon and reacting with all products of proglucagon (mainly glucagon, glicentin, and oxyntomodulin) which contain this sequence, was used together with monoiodinated ${ }^{125} \mathrm{I}$-labeled glucagon and standards of porcine glucagon as described previously (24). For GLP-1 assays, antibody 2135 , directed at the mid-to-C-terminal part of GLP-1 and reacting with all products of proglucagon which contain this sequence [mainly GLP-1 (7-36 amide); GLP-1 (1-36 amide); the glycine-extended forms of the latter peptides; and the major proglucagon fragment (MPF or proglucagon $72-158)$ ] was used together with monoiodinated ${ }^{125}$ I-labeled GLP-1 (7-36 amide) and standards of human GLP-1 (7-36 amide) as described previously (25). Rat plasma was diluted 10 times with assay buffer $(24,25)$ to avoid extraction. Under these circumstances the detection limits of the assays were $10-20 \mathrm{pM}$ and the intraassay coefficient of variation was $10 \%$ at a level of $100 \mathrm{pM}$. Recovery of glucagon and GLP-1 (7-36 amide) added to rat plasma and assayed immediately thereafter deviated $<20 \%$ from expected values. Insulin was quantified as described (26).

Immunohistochemistry. The tail region of the pancreas was collected for hormone immunochemistry, in situ hybridization, and in situ apoptosis staining and fixed in $4.3 \%$ buffered formalin, $\mathrm{pH} 7.3$ (Bie \& Berntsen, Rødovre, Denmark) overnight and processed for paraffin sectioning. In a parallel group of rats, pancreata were processed for cryostat sectioning required for immunocytochemical demonstration of IPF1/ STF1. Fresh pancreata were embedded in Tissue Tek (Miles Inc., Elkhart, IN) and frozen in isopentane (prechilled in dry ice/ethanol) before sectioning $(3 \mu \mathrm{m})$. Immunoperoxidase stainings for insulin, glucagon, and rat C-peptide 1 and 2 were performed as described (27) and rabbit anti-rat STF1 antiserum, kindly provided by Dr. Marc Montminy (Salk Institute, La Jolla, CA), was used as described (22).

DNA probes and synthesis. Biotinylated DNA probes were synthesized using a DNA synthesizer (model 392/394; Applied Biosystems, Foster City, CA) according to Applied Biosystems User Bulletin No. 70, using phosphoamidites (Cruachem Ltd., Glasgow, United Kingdom) and biotin-ON phosphoamidites (Clontech, Palo Alto, CA). The antisense probes were: rat proinsulin 1, GTG GGC GGG GAG TGG TGG ACT CAG TTG C -BCB TBC; rat proinsulin 2, TGG ACA GGG TAG TGG TGG GCC TAG TTG C -BCB TBC; and rat proglucagon, TTT GAG TGT GTT CTG CGC CCA AGC TCT GCC CT -BCB TBC (B $=$ biotinylated phosphoamidite). All probes were directed to sequences in the untranslated $5^{\prime}$ end of the respective mRNA.

In situ hybridization. In situ hybridization was performed using a modification of a previously described method (28). Sections mounted on silane-coated glass slides (29) were deparaffinized (27) and washed for $10 \mathrm{~min}$ in TBS containing $50 \mathrm{mM}$ Tris $/ \mathrm{HCl}(\mathrm{pH} \mathrm{7.4)}$ and 150 $\mathrm{mM} \mathrm{NaCl}$. Proteinase $\mathrm{K}$ solution (Boehringer Mannheim, Mannheim, Germany), $10 \mu \mathrm{g} / \mathrm{ml}$ in $100 \mathrm{mM}$ Tris $/ \mathrm{HCl}$ ( $\mathrm{pH} \mathrm{8.0)}$ ), predigested a $37^{\circ} \mathrm{C}$ for $45 \mathrm{~min}$ to remove RNase activity, was then used to digest the sections for 20 or 25 min for hybridization with insulin or glucagon probes, respectively. The sections were postfixed in $4 \%$ paraformaldehyde (wt/vol) in PBS containing $136.8 \mathrm{mM} \mathrm{NaCl}, 2.7 \mathrm{mM} \mathrm{KCl}, 8.0$ $\mathrm{mM} \mathrm{Na} \mathrm{HPO}_{4}, 1.5 \mathrm{mM} \mathrm{KH} \mathrm{PO}_{4}(\mathrm{pH} \mathrm{7.2)}$ for $5 \mathrm{~min}$, washed $3 \times 5$ min in PBS containing $0.2 \%$ glycine (wt/vol), dehydrated in an ascending EtOH gradient (70-96-99\%) for $5 \mathrm{~min}$ each, and delipidized in chloroform for $10 \mathrm{~min}$. Sections were then washed in $99 \% \mathrm{EtOH}$ for 5 $\mathrm{min}$, dried under vacuum for $2 \mathrm{~h}$, and were then ready for hybridization. Biotinylated deoxynucleotide probe $(5 \mu \mathrm{g} / \mathrm{ml})$ in hybridization buffer $3 \times$ SSC containing $50 \%$ formamide ( $\mathrm{vol} / \mathrm{vol}$ ), $7.5 \%$ dextran sulfate (wt/vol), $0.1 \%$ herring sperm DNA (wt/vol) was added in a volume of $200 \mu \mathrm{l}$ to each dried section. The sections were sealed with a coverslip and incubated in a humidified chamber overnight at $40-42^{\circ} \mathrm{C}$. The coverslip was soaked off and sections were washed in $0.1 \times \mathrm{SSC}$ at increasing temperatures $\left(40-45-50^{\circ} \mathrm{C}\right)$ for $30 \mathrm{~min}$ each, in TBS for 5 min, and then the following were added: blocking buffer, TBS containing $1 \%$ BSA (wt/vol), and $0.1 \%$ Triton X-100 ( vol/vol) for $2 \mathrm{~min}$. The blocking buffer was tapped off and the sections were incubated for 30 min with mouse monoclonal antibiotin antibodies (M743; Dako Corp., Carpinteria, CA) diluted 1:100 in TBS. After washing in TBS ( $3 \times 5 \mathrm{~min}$ each), sections were incubated for $30 \mathrm{~min}$ in biotin-labeled goat anti-mouse IgG antibodies (E433; Dako Corp.) diluted 1:300 in TBS containing $0.25 \%$ BSA (wt/vol). This reagent was preabsorbed for crossreactivity to rat immunoglobulins in $2.5 \%$ ( $\mathrm{vol} / \mathrm{vol}$ ) nonimmune rat serum for $1 \mathrm{~h}$. Sections were then washed $3 \times 5 \mathrm{~min}$ in TBS and incubated with alkaline phosphatase-conjugated streptavidin (D396; Dako Corp.) diluted 1:100 in TBS for $30 \mathrm{~min}$. Sections were then washed $3 \times 5 \mathrm{~min}$ in TBS, once in alkaline phosphatase buffer containing $100 \mathrm{mM}$ Tris/ $\mathrm{HCl}$ (pH 9.5), $100 \mathrm{mM} \mathrm{NaCl}, 5 \mathrm{mM} \mathrm{MgCl}$, and then developed in alkaline phosphatase buffer containing $0.035 \%$ nitro blue tetrazolium (wt/vol), $0.0175 \%$ 5-bromo-4-chloro-3-indolyl phosphate ( $\mathrm{wt} / \mathrm{vol}$ ), and $0.5 \mathrm{mM}$ levamisole for $20 \mathrm{~min}$. The chromogen reaction was stopped in $5 \mathrm{mM}$ EDTA for $1 \mathrm{~h}$. The sections were mounted with a coverslip and examined by light microscopy. Sections incubated without specific oligonucleotide sequences or with sense oligonucleotides served as negative controls.

Morphometry. A, D, and PP cells were immunocytochemically visualized in three groups of animals (GLU-, IN-, and control rats; $n=6$ in each group) by staining for glucagon, somatostatin, and pancreatic polypeptide, respectively, and were counted per individual islet ( $n$ $=55-210$ per animal per staining) in serial pancreatic sections. Only nucleated cells were counted. Using computer-aided image analysis, the areas of all islets examined were planimetrically measured by manual tracing of the islet borderline with the cursor $(n=217-507$ for each animal in groups of 6). The mean size of the islets and number of positive cells per square millimeter of islet were calculated. Since the mean islet size in tumor-transplanted animals was found to be decreased compared with controls, the number of cells per square millimeter obtained from tumor-transplanted animals was corrected by multiplication with the shrinkage factor $(0.76$ for GLU-rats and 0.67 for IN-rats, see Results). The numbers of cells per square millimeter in tumor-bearing animals are thus normalized to controls in terms of islet size. This correction was necessary to directly visualize changes in the abundance of individual islet cell types in comparison to controls.

The mean planimetrical B cell size was measured by counting the number of nuclei in randomly selected squares of $50 \times 50 \mu \mathrm{m}$ placed in the B cell compartment by using sections stained for glucagon to define the B cell core ( 25 squares/animal). The mean size of acinar cells was measured by counting the number of nuclei in randomly selected squares of $200 \times 200 \mu \mathrm{m}$ in the exocrine tissue ( 10 squares/ animal). Statistical significance was assumed at $P<0.05$ using the two-tailed unpaired Mann-Whitney U test.

In situ detection of apoptotic cells. The sections were deparaffinized, rehydrated in PBS (as above), and incubated with either terminal deoxynucleotide transferase of the ApopTag in situ apoptosis detection ki essentially as described by the supplier (Oncor Inc., Gaithersburg, MD) or by the TUNEL-assay (30) using terminal deoxynucleotide transferase (Boehringer Mannheim) as described by Gorczyca et al. (31). Apoptotic cells were detected using an alkaline phosphatase-labeled antidigoxigenin Fab fragment (Boehringer Mannheim) followed by development in nitro blue tetrazolium/5-bromo-4-chloro-3-indolyl phosphate as described above. The ApopTag and the TUNEL-assay produced identical 

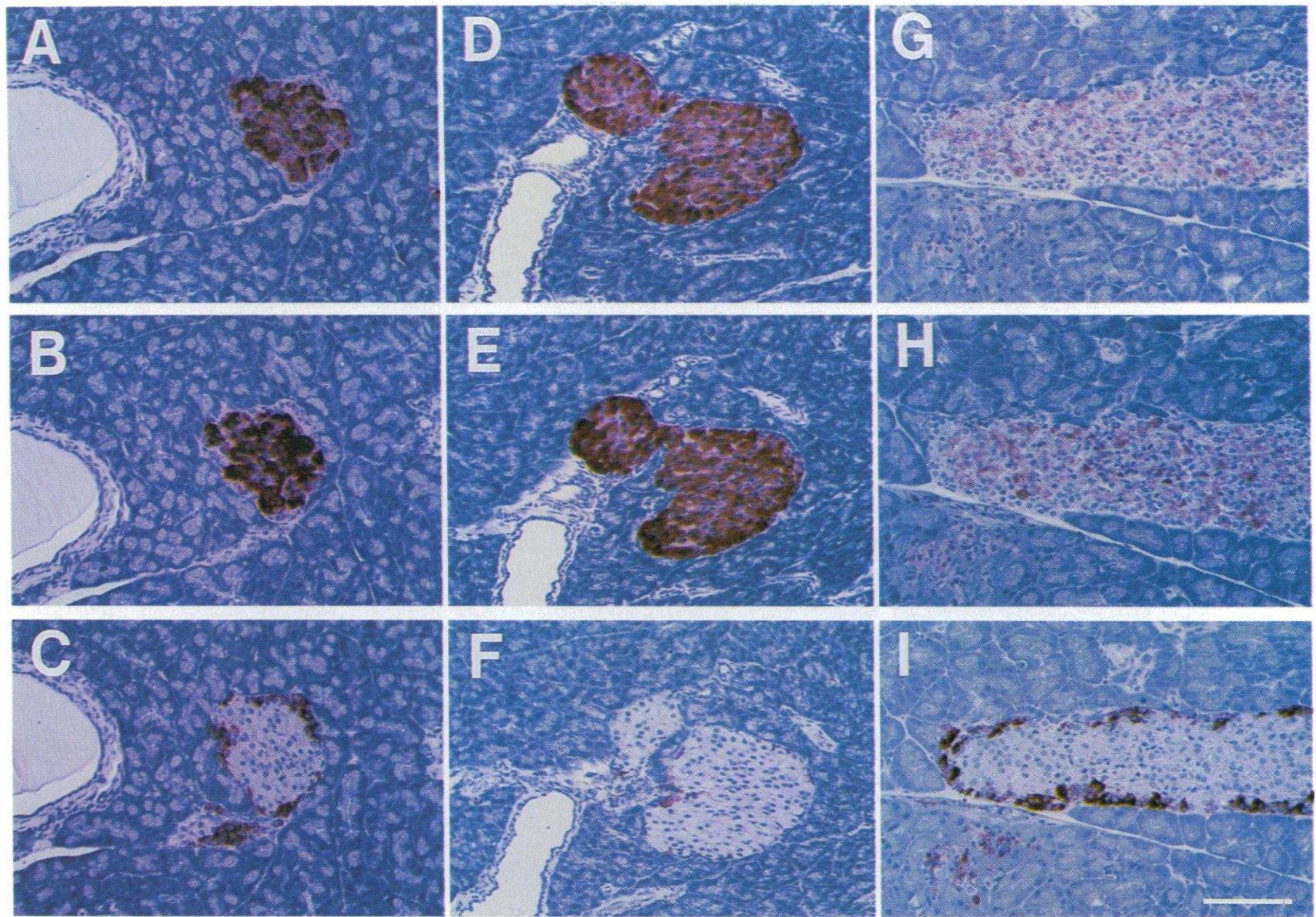

Figure 1. Indirect immunoperoxidase staining of serial pancreatic islet sections (red staining). Control rat $(A-C)$, GLU-rat $(D-F)$, and IN-rat $(G-I) . A, D$, and $G$ : proinsulin C-peptide $1 ; B, E$, and $H$ : proinsulin C-peptide 2; $C, F$, and $I$ : glucagon. A selective reduction in staining intensity for glucagon and the two proinsulin C-peptides is observed in GLU- and IN-rats, respectively. Bar, $100 \mu \mathrm{m}$.

results. The number of apoptotic cells in islet and acinar tissue was quantified as above by counting stained nuclear bodies per area. Using the estimated average cell size from the different compartments in the different groups of animals we then calculated the apoptotic index (i.e., percentage of apoptotic cells) for islets and for acinar tissue.

\section{Results}

Tumor influence on circulating hormone levels. Rats transplanted with MSL-G-AN glucagonoma tissue (GLU-rats) grad-
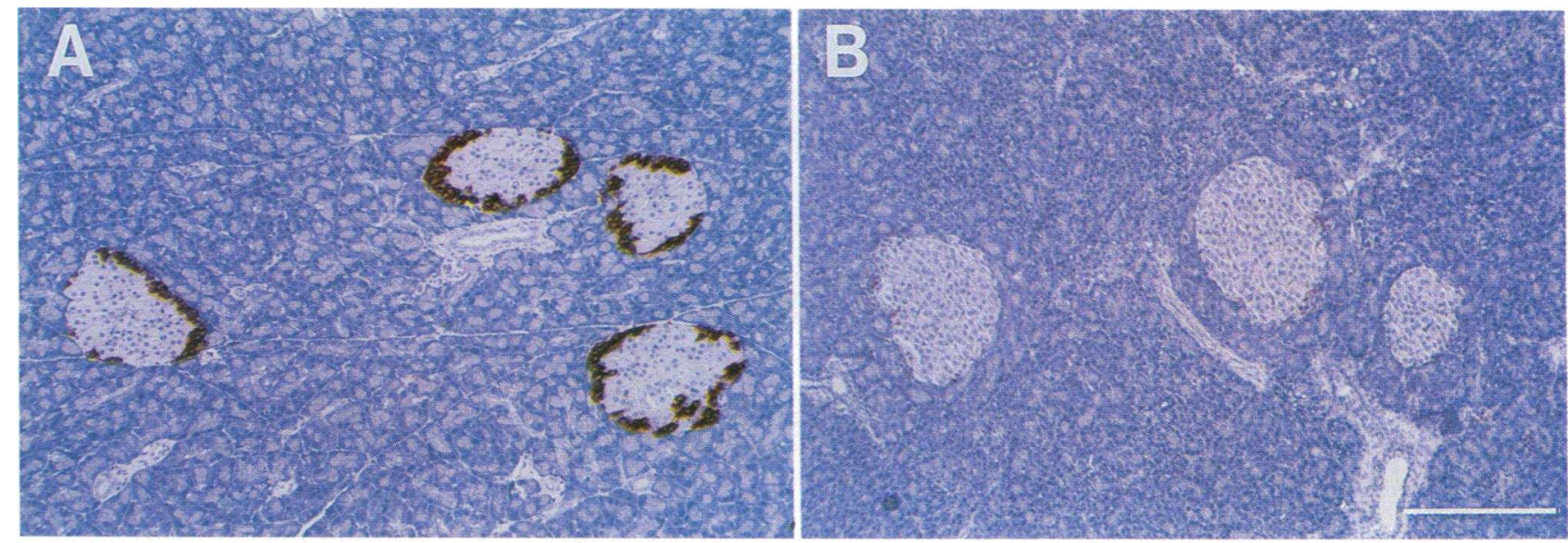

Figure 2. Representative indirect immunoperoxidase staining for glucagon on pancreatic sections (red staining) from a control rat (A) and a GLUrat $(B)$. Notice the increased cell density of the GLU-pancreas as well as the severe reduction in glucagon staining intensity. Bar, $200 \mu \mathrm{m}$. 

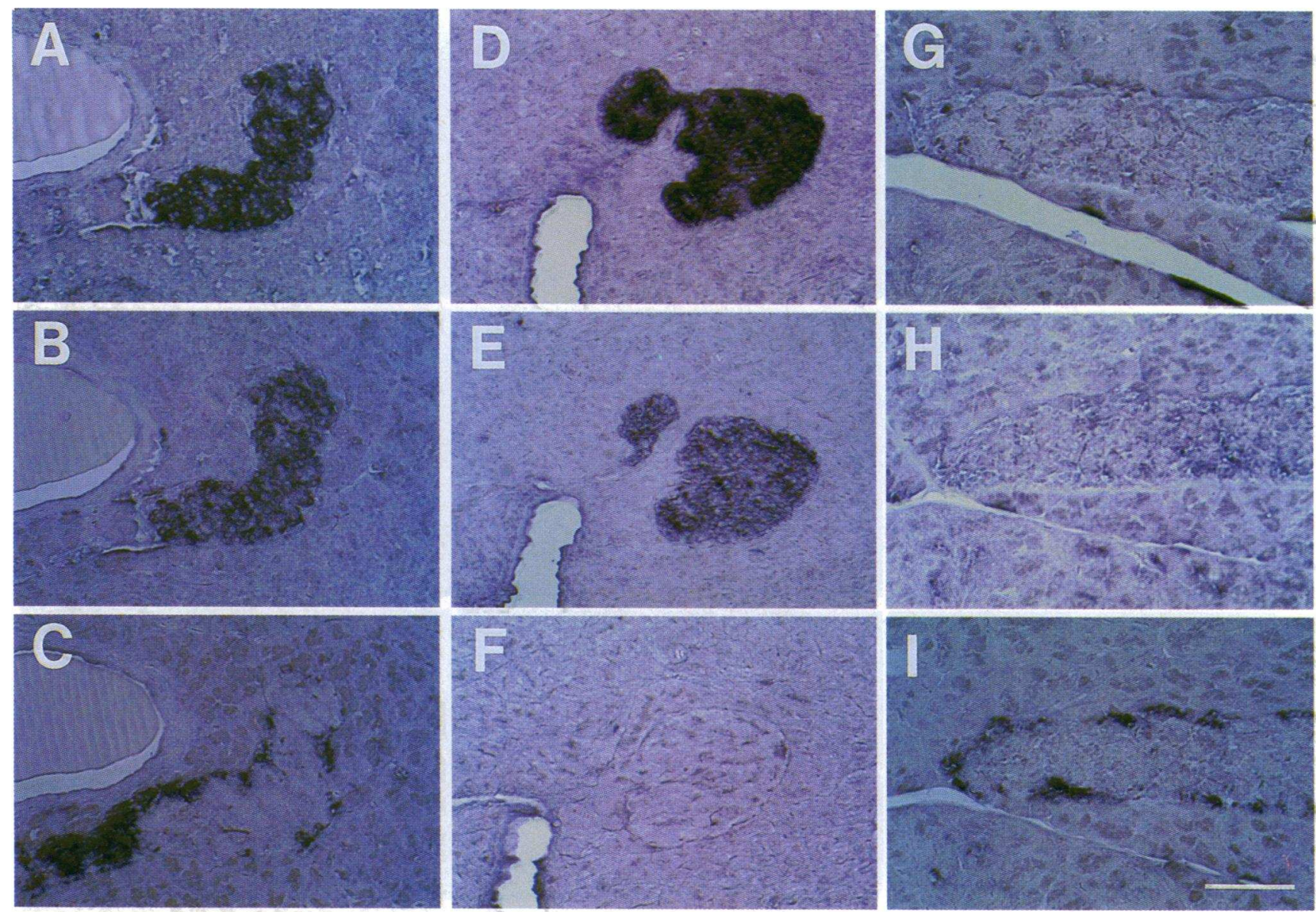

Figure 3. In situ hybridization staining of pancreatic islet sections adjacent to those shown in Fig. 1 (dark blue staining). Control rat $(A-C)$, GLUrat $(D-F)$, and IN-rat $(G-I) . A, D$, and $G$ : proinsulin 1 mRNA; $B, E$, and $H$ : proinsulin 2 mRNA; $C, F$, and $I$ : proglucagon mRNA. A selective reduction in staining intensity for the mRNAs encoding proglucagon and the two proinsulins is observed in GLU- and IN-rats, respectively. Bar, $100 \mu \mathrm{m}$.

ually developed a tumor of $\sim 0.5-1$ grams which was followed by acute onset of anorexia and weight loss ( $32 \pm 8 \%$ weight loss at time of killing). Anorectic rats were slightly hypoglycemic (3.6 $\pm 0.7 \mathrm{mM}, n=8$; compared with control rats: $4.6 \pm 0.7 \mathrm{mM}$, $n=8)$, which may reflect the anorexia-induced starvation. Rats transplanted with the MSL-G2-IN insulinoma (IN-rats) developed a tumor of similar size and severe hypoglycemia $(2.2 \pm 0.6 \mathrm{mM}$ at time of killing, $n=8)$, but showed normal weight gain. All tumor-transplanted animals appeared otherwise normally active. Circulating glucagon and GLP-1 levels in GLU-rats were significantly elevated compared with controls (glucagon: $3,233 \pm 1,044$ vs. $47 \pm 14 \mathrm{pM} ; P<0.005$ ) (GLP-1: $2,342 \pm 1,243$ vs. $30 \pm 11 \mathrm{pM} ; P<0.005)$. Likewise, circulating insulin in IN-rats was significantly increased $(4,303 \pm 1,972 \mathrm{pM})$ compared with controls $(574 \pm 191 \mathrm{pM} ; P<0.005)$. Interestingly, in GLU-rats there was a more than sixfold reduction in circulating insulin $(89 \pm 37 \mathrm{pM} ; P<0.005)$ compared with controls. In IN-rats, circulating glucagon and GLP-1 levels were identical to control values.

Immunocytochemistry. To examine effects of the transplantable tumors on the endocrine cells, serial pancreatic sections were stained with antibodies to glucagon, proinsulin C-peptide 1 and C-peptide 2 (Fig. 1), somatostatin, and pancreatic polypeptide (not shown). In GLU-rat islets, the glucagon staining was dramatically reduced (Fig. 1, $F$ compared with $C$ ), whereas the proinsulin C-peptide 1 and 2 stainings (Fig. 1, D and $E$ ) were comparable with those of control rats in intensities (Fig. $1, A$ and $B$ ). The reduction in the glucagon staining intensity in GLU-rats was observed in all animals, and when the islets were examined under low power magnification, as shown in Fig. 2 , in three out of six rats the staining was essentially negative. In IN-rats, the opposite was observed. Both proinsulin C-peptide 1 and 2 stainings ranged from clearly reduced to negative (Fig. $1, G$ and $H$ ), whereas the glucagon staining was comparable with that of controls (Fig. $1 \mathrm{I}$ ). Of the six animals examined, the islets of the two with the highest circulating insulin levels were essentially negative for both C-peptide 1 and 2 . Furthermore, both proinsulin C-peptide immunoreactivities were reduced to a comparable degree in all $\mathrm{IN}$-rats. No obvious differences in staining intensity were observed between tumor-transplanted animals and control animals when stained for somatostatin or pancreatic polypeptide (not shown).

In situ hybridization. To investigate whether the reduction in islet hormone content was due to decreased mRNA levels, in situ hybridization for proglucagon and proinsulin 1 and 2 mRNA was performed on adjacent serial pancreatic sections (Fig. 3). These stainings paralleled the immunostainings (Fig. 3 vs. Fig. 1). Thus, the downregulation of the corresponding 

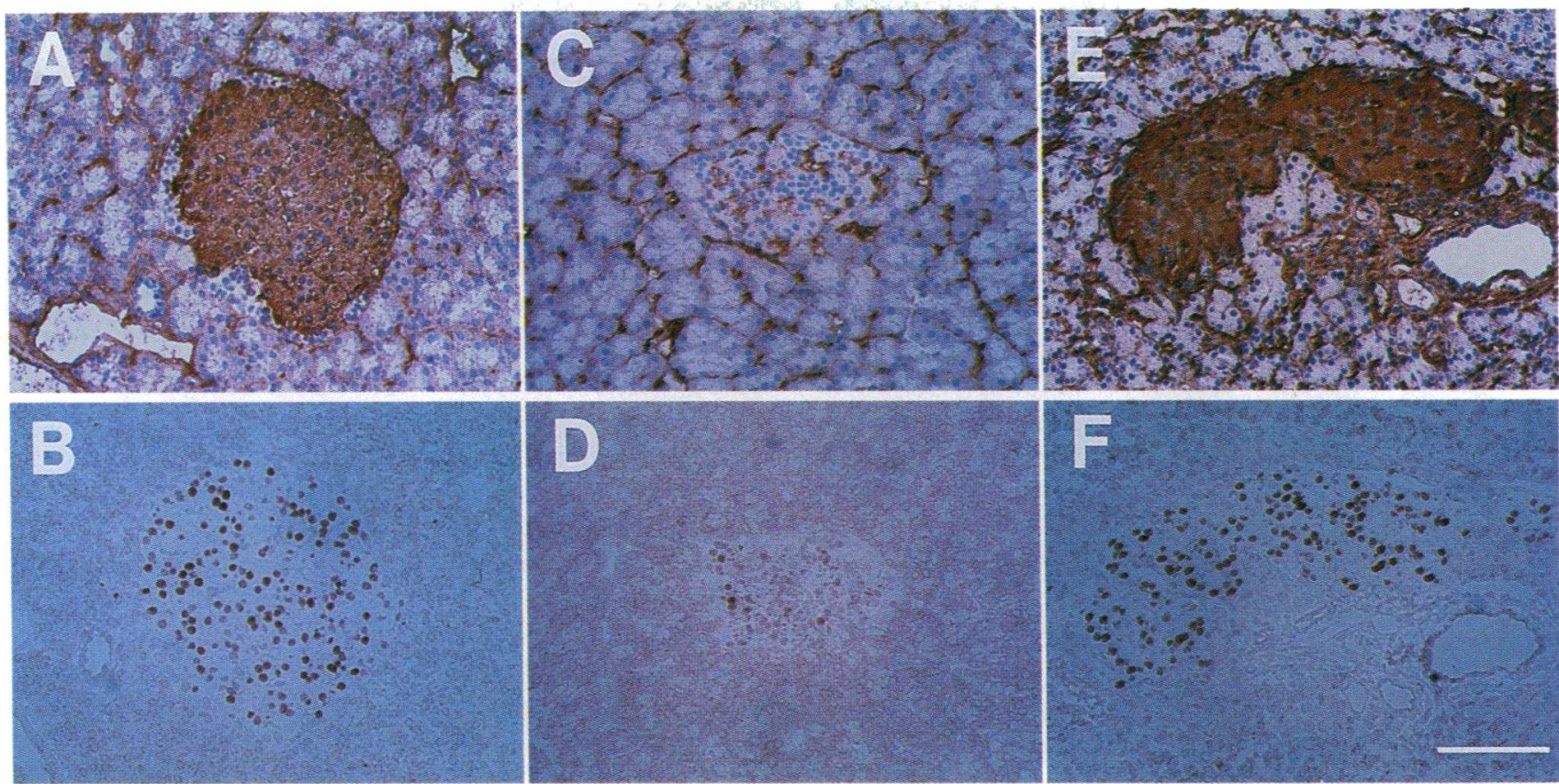

Figure 4. Indirect immunoperoxidase staining on serial frozen pancreatic sections (red stain). $A$ and $B$ : control rat; $C$ and $D:$ IN-rat; $E$ and $F$ : GLU-rat. $A, C$, and $E$ : insulin; $B, D$, and $F$ : STF1. $A, C$, and $E$ are counterstained with hematoxylin (blue staining). Notice the severe reduction in staining intensity for insulin as well as for STF1 in the IN-rat islet ( $C$ and $D$ ) compared with the control $(A$ and $B)$ and GLU-rat islets ( $E$ and F). Bar, $100 \mu \mathrm{m}$.

endogenous hormone ( $s$ ) by the transplanted glucagonomas and insulinomas was reflected at the mRNA level, suggesting transcriptional inhibition.

Tumor influence on islet expression of the insulin transcription factor IPF1/STF1. To further assess if the tumor-induced $B$ cell inhibition was reflected at the level of cell-specific transcription factors, we performed stainings for IPF1/STF1 (Fig. 4). The IPF1/STF1 staining in normal adult rat islets is almost entirely confined to B cell nuclei (Fig. $4 \mathrm{~B}$ ) as well as to a small fraction of somatostatin cells (23). The IN-rats showed a severe reduction in STF1 staining intensity (Fig. $4 D$ ) compared with controls (Fig. $4 \mathrm{~B}$ ) and GLU-rats (Fig. $4 F$ ). This suggests that the lack of adequate amounts of the transcription factor STF1 or similar transcription factors could be involved in transcriptional inhibition of proinsulin 1 and 2 gene expression (Fig. $4, C$ vs. $A$ and $E$ ).

Morphometry. To further evaluate the effects of the glucagonomas and insulinomas on the islet cell populations, quantitation of immunoreactive A, D, and PP cells was performed and mean islet area was measured by image analysis. The number of the different cell types per islet area is shown in Fig. 5. The GLU-rats showed a highly significant and selective reduction in the number of glucagon positive A cells (Fig. 5). In addition, most of the positively scored glucagon containing A cells actually showed reduction in cytoplasm as well as in staining intensity. The number of D cells in the GLU-rats was slightly but significantly increased compared with controls and IN-rats, whereas the number of PP cells was unchanged in all groups (Fig. 5). Also, the pancreatic islet volume was reduced in both types of tumor-transplanted animals as can be seen by the decrease in average planimetrical areas: $76 \pm 12 \%$ in GLU-rats and $67 \pm 13 \%$ in IN-rats compared with controls (Fig. $6 \mathrm{~A}$ ).

For indirect determination of the fate of the A cells in GLUrats, we performed stainings with a mixture of antibodies to glucagon, insulin, somatostatin, and pancreatic polypeptide (Fig. 7) and found a fraction of islets containing densely packed immunonegative peripheral cells (Fig. $7 B$ ). Such cells were not found in control or IN pancreata (Fig. 7, $A$ and $C$ ) and are most likely A cells without glucagon expression. From Fig. 6 $B$ it was moreover evident that a reduction in the average $B$ cell size also contributes significantly to islet reduction in GLUrats. Based on immunocytochemical stainings the $B$ cells appeared active; however, the density of $\mathrm{B}$ cells was contracted in size to a similar extent $(60 \pm 11 \%)$ as that observed for the surrounding acinar cells $(55 \pm 8 \%)$ when compared with controls (Fig. 6, $B$ and $C$ ). It thus appeared that reduced cell volume was common for most pancreatic cell types (acinar and B cells) in GLU-rats and might be a likely consequence of the severe

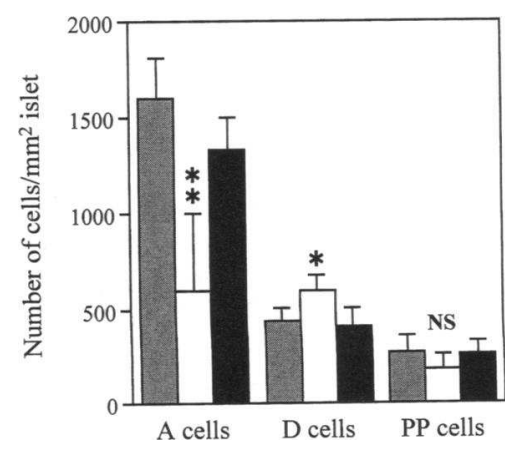

Figure 5. Number of A, $\mathrm{D}$, and PP cells counted per square millimeter of islet area in sections from control (gray bars), GLU- (white bars), and IN-rats (black bars). Values for GLU- and INrats were normalized to control islet area to correct for islet shrinkage (see Methods). Bars indicate the mean \pm SD. A highly significant reduction in the number of the glucagon-positive cell population is seen in GLU-rat islets $(* * P<0.005)$ as well as an increase in the number of somatostatin-positive cells $(* P<0.05)$. No significant difference between the pancreatic polypeptide-positive cells was found between any groups. 
Size (\% of control)
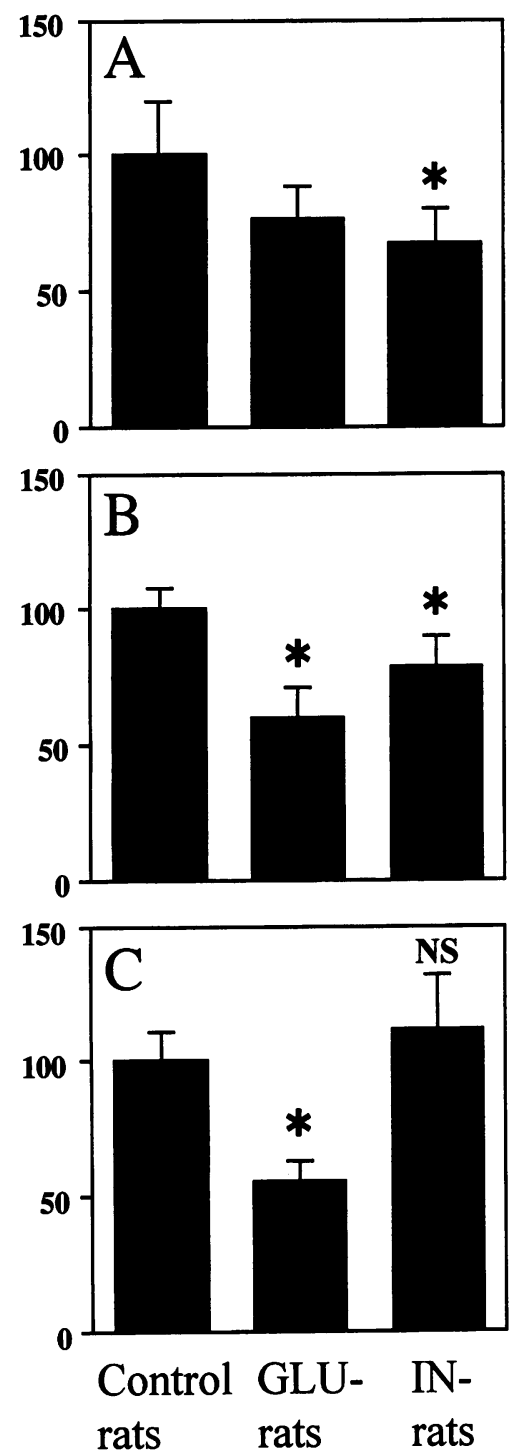

Figure 6. Morphometry. (A) Mean islet area compared with controls. Both the GLU-rats as well as the IN-rats showed reduction in islet size $(* P$ $<0.05$ ). (B) Average cell size in the B cell compartment compared with controls. Both GLU-and IN-rats showed highly significant decreases in the cell size within the B cell compartment $(* P$ $<0.005$ ), however, they were most pronounced in GLU-rats. ( $C$ ) Average acinar cell size compared with controls. The GLUrats showed a highly significant reduction of acinar cell size $\left({ }^{*} P\right.$ $<0.005)$, whereas INrats were not significantly different from controls (NS). The decrease in $\mathrm{B}$ and acinar cell size was similar in GLU-rats $(B$ and $C)$. Bars indicate the mean \pm SD ( $n=6$ animals for each group).

weight loss in these animals. The contraction of exocrine tissue in GLU-rats versus controls was also evident in Fig. 2.

The nature of the islet atrophy in IN-rats with an apparently unchanged A, D, and PP cell compartment (Fig. 5) was quite different from that observed in GLU-rats. The size of B cells was decreased to $79 \pm 11 \%$ while mean exocrine cell density remained unchanged compared with controls (Fig. 6, $B$ and $C)$. Although the islets of IN-rats showed a more pronounced reduction in size than in GLU-rats (Fig. $6 \mathrm{~A}$ ), the B cell compartment of IN-islets still contained larger cells when compared with GLU-islets (Fig. $6 \mathrm{~B}$ ). This indicated that B cells were being eliminated from the islets of IN-rats.

Tumor-induced pancreatic apoptosis. To investigate the phenomenon of the reduction in islet cell number in IN-versus GLU- and control animals, sections were stained for apoptotic cells with DNA strand breaks (Fig. 8). A significant number of apoptotic cells was found in the islet $B$ cell compartment of the pancreas of IN-rats (Fig. 8, $A$ and $B$, and Table I) while essentially no apoptotic cells were found within islets of control or GLU-rats (Fig. 8, $C$ and $D$, and Table I). No obvious signs of inflammation was observed in any islets with apoptosis.

Surprisingly, a highly significant increase in the frequency of scattered apoptotic cells was found in the exocrine pancreas of all GLU-rats, selectively, whereas no indication of apoptosis in A cells or in the similarly condensed B cell population was seen (Fig. 8, $C-E$, and Table I). Apoptotic cells were observed with a low frequency in the acinar tissue of control- and INrats (Table I). As expected, apoptotic cells were common in pancreatic lymph nodes of control and tumor-transplanted rats (not shown).

\section{Discussion}

We have shown that transplantable insulinomas and glucagonomas derived from common clonal origin have a profound and selective inhibitory effect on the endogenous islet B and A cells, respectively. The corresponding endogenous hormone genes are essentially turned off, pointing to the existence of a powerful negative feedback mechanism of unresolved nature which eventually results in islet atrophy. The islet changes observed in the two groups of transplanted animals are controlled by fundamentally different mechanisms as discussed below.

Glucagonoma-induced changes of the endogenous pancreas. The inhibitory effects on pancreatic A cells by the MSLG-AN glucagonoma are in agreement with recently published observations involving mouse, hamster, and rat glucagonomas transplanted into nude mice $(1,2)$. A major difference of the MSL-G-AN tumor from previously published experimental glucagonomas is the associated anorexia/adipsia $(8,9)$ which leads to severe weight loss as also frequently observed in the glucagonoma syndrome in humans (for review see reference 10). Here we show that the observed islet atrophy is composed of a retraction of A cell cytoplasm associated with a reduction in glucagon mRNA, as well as a reduction of mean B cell size. Taking into account that exocrine tissue is also contracted to a similar degree compared with B cells in GLU-rats (40-50\%), the overall islet size reduction is not significantly different from the general contraction of pancreatic tissue. Therefore, the dramatic A cell atrophy observed is highly selective in these animals and most likely directly associated to the glucagonoma phenotype, while the general contraction of pancreatic tissue (acinar and B cells) might be a consequence of the poor nutritional status of the anorectic GLU-rats. The A cell atrophy was characterized by loss of A cell cytoplasm resulting in densely packed nuclear structures in the periphery of the islets. Several older reports show similar A cell inhibition in response to prolonged glucagon treatment (32-36), thus suggesting a central role for glucagon in the feedback mechanism of the glucagonoma-induced A cell inhibition. Similarly, GLP-1 has been shown to inhibit pancreatic glucagon biosynthesis and secretion (37-41). GLP-1, which is cosecreted by MSL-G2-AN (8), may thus add to the inhibitory effect of glucagon on the endogenous A cells.

The exocrine compartment of GLU-rats showed a highly significant elevation in the frequency of apoptotic cells when compared with IN-rats and controls. It is possible that the anorexia-induced starvation triggers the apoptotic pathway in acinar cells as a general mechanism to rescue nutrients from apparently redundant tissue. No apoptosis was detected within the islets of GLU-rats despite A cell atrophy and the fact that the B cell compartment was condensed to the same degree as the exocrine tissue (Fig. 8, $C$ and $D$, and Table I). Although these animals had a sixfold reduction of circulating insulin, their B cells appeared clearly active with respect to proinsulin 1 and 2 


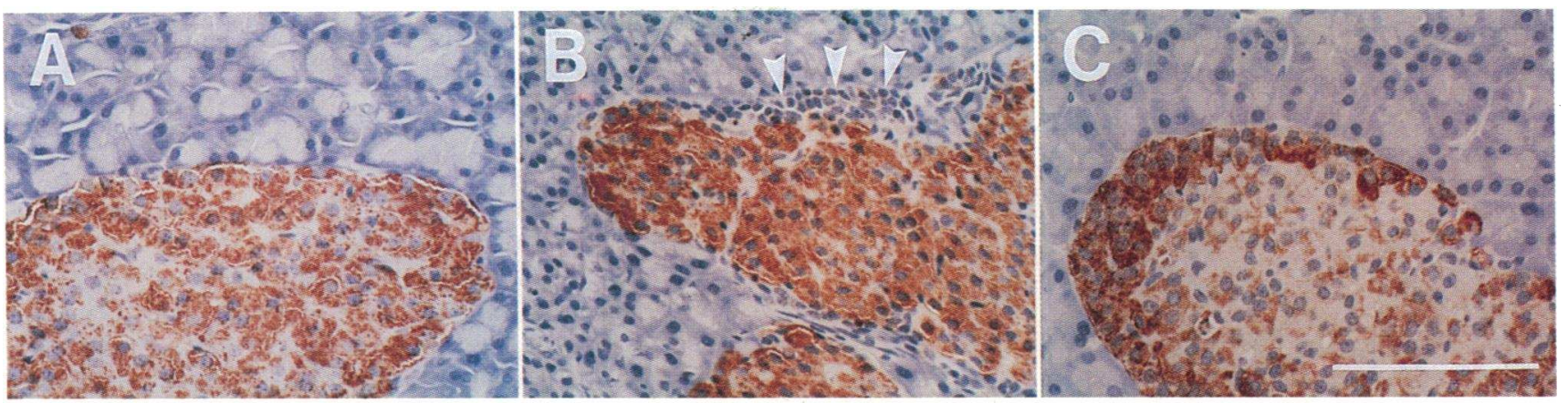

Figure 7. Indirect immunoperoxidase staining of islet sections with a mixture of antibodies for glucagon, insulin, somatostatin, and pancreatic polypeptide (red staining). Control rat islet $(A)$, GLU-rat islet $(B)$, and IN-rat islet $(C)$. Notice the densely packed cells with reduced cytoplasm marked with arrows in the GLU-rat islet, as well as the increased density of acinar cells $(B)$. Bar, $100 \mu \mathrm{m}$.

(Figs. 1 and 3) as well as STF1 (Fig. 4) biosynthesis. Reduced insulin secretion is a normal body defense to starvation and serves to maintain blood glucose for the vital brain function. The physiological significance of the sparing of an apparently active B cell compartment as observed in anorectic GLU-rats could be the importance of an efficient insulin response upon refeeding as a natural consequence of prolonged fasting.

Insulinoma-induced islet $B$ cell loss by apoptosis. Impairment of pancreatic $B$ cell function by transplantable insulinomas has been reported previously by other groups $(3-5,42)$. We now show by in situ hybridization that the impairment of proinsulin biosynthesis occurs at the mRNA level for both insulin genes. Interestingly, the transcription factor IPF1/STF1, which is critical for fetal pancreatic development (20) and a key component in regulation of insulin gene transcription in the adult B cell $(18,21-23)$, was found to be strongly downregulated in most pancreatic B cells of the IN-rats. It is therefore likely that this negative feedback mechanism affects synthesis of cellspecific transcription factors possibly specifying the differentiated $B$ cell phenotype.

The phenomenon of $\mathrm{B}$ cell inhibition is also seen after chronic overinsulinization of normal rats (43). Glucose infusions in insulinoma-bearing rats that reestablish euglycemia also restore B cell function $(44,45)$. Similarly, downregulation of
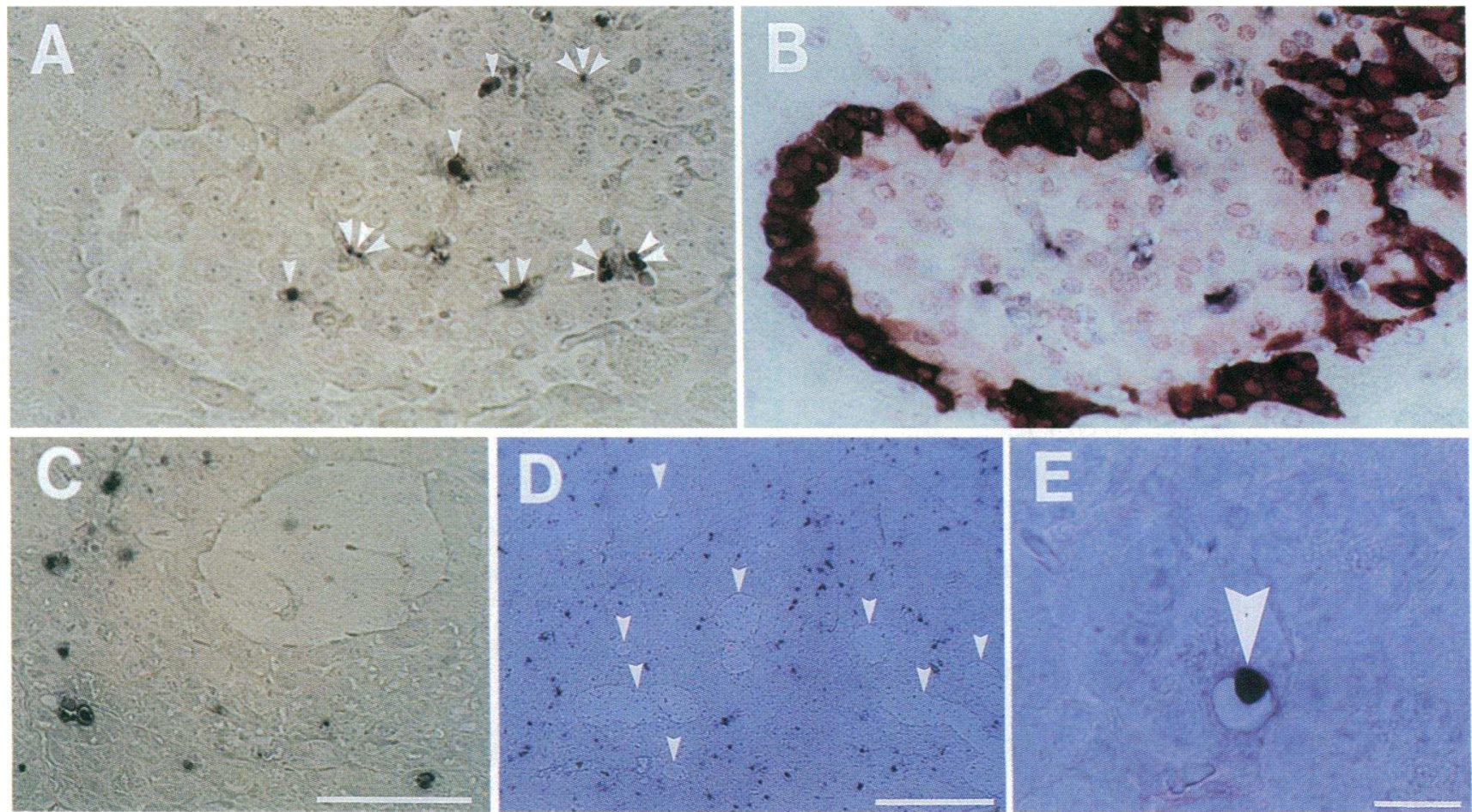

Figure 8. Indirect in situ staining for apoptotic cells (black staining) on pancreatic sections. $A$ and $B$ : IN-rat islet sections; $C-E$ : pancreatic sections from GLU-rats. $(A)$ Characteristic apoptotic cells in IN-rat islet, where increasing numbers of arrows indicate progressing stages of the apoptotic process. $(B)$ The same IN-rat islet section double-stained for glucagon (red peripheral staining) and apoptotic cells within the B cell compartment (black staining). As can be seen, the apoptotic cells are confined within the B cell compartment. ( $C$ ) GLU-rat islet surrounded by apoptotic exocrine cells. $(D)$ Low magnification of GLU-rat pancreatic section, showing high density of apoptotic cells in the exocrine tissue, whereas no apoptotic cells can be seen within islets (arrows). $(E)$ Characteristic apoptotic cell (arrow) separating from neighboring cells in the exocrine pancreas of the GLU-rat. $A-C$, same scale, bar, $50 \mu \mathrm{m} ; D$, bar, $500 \mu \mathrm{m} ; E$, bar, $10 \mu \mathrm{m}$. 
Table I. Pancreatic Apoptosis in GLU- and IN-Rats versus Controls

\begin{tabular}{|c|c|c|c|c|c|}
\hline \multicolumn{3}{|c|}{ Islet apoptotic index (\%) } & \multicolumn{3}{|c|}{ Exocrine apoptotic index (\%) } \\
\hline Control & GLU & $\mathbf{I N}^{*}$ & Control & GLU* & IN \\
\hline 0.00 & 0.00 & 1.76 & 0.01 & 0.18 & 0.02 \\
\hline 0.01 & 0.00 & 1.69 & 0.02 & 0.69 & 0.01 \\
\hline 0.00 & 0.00 & 0.03 & 0.03 & 0.36 & 0.01 \\
\hline 0.00 & 0.00 & 0.59 & 0.05 & 0.63 & 0.01 \\
\hline 0.02 & 0.00 & 0.03 & 0.03 & 0.50 & 0.01 \\
\hline 0.00 & 0.00 & 0.05 & 0.02 & 1.79 & 0.04 \\
\hline \multirow[t]{2}{*}{0.00} & 0.00 & 0.20 & 0.03 & 0.72 & 0.01 \\
\hline & 0.00 & 2.01 & & 0.16 & 0.02 \\
\hline
\end{tabular}

The islet and exocrine apoptotic index in control $(n=7)$, GLU-rats $(n$ $=8$ ), and IN-rats $(n=8)$. Mean apoptotic islet indexes were $0.00,0.00$, and $0.80 \%$, respectively. Mean apoptotic exocrine indexes were 0.03 , 0.63 , and $0.01 \%$, respectively. ${ }^{*}$ Islet indexes in IN rats and the exocrine index in GLU-rats are significantly increased from those observed in the two other groups $(P<0.0005)$.

proinsulin and islet amyloid polypeptide mRNA by insulin infusions is reversed by coinfusions with glucose (46). Taken together, these reports indicate that prolonged hypoglycemia rather than hyperinsulinemia is a key component in the negative feedback loop causing B cell inhibition and decreased B cell mass. However, an inhibitory effect on pancreatic B cell activity of insulin by itself in euglycemic glucose-clamped rats has also been reported (47).

We have confirmed that islet atrophy in insulinoma-transplanted rats selectively affects the B cell compartment $(5,6)$ and that this phenomenon is characterized by induction of programmed cell death of the B cells. The residual and almost inactive B cells were selectively condensed compared with the average exocrine cell density in IN-rats as well as to average B cell density of control rats. The observed maximal apoptotic index in the range of $2 \%$ combined with the rapid nature of the apoptotic process $(2-3 \mathrm{~h})(48)$ predicts that a time window of just a few days would be sufficient to account for the observed atrophy. The process of B cell elimination is most likely tightly controlled based on the observed range of apoptotic index (from 0.03 to $2.01 \%$ in eight IN-rats, Table I and Fig. 8), which may reflect the actual variation in severity and duration of hypoglycemia in this group of rats. Low values would predict that these rats might either not have entered or, alternatively, already exited the short time phase of maximal destruction. Importantly, no sign of lymphocytic infiltration was observed in any islet of the IN-rats.

The dynamic B cell mass. The B cell mass is known to respond to long-term glucose-driven changes by hyperplasia in the hyperglycemic state $(49$, for reviews see references 50 and 51 ) and by atrophy in the hypoglycemic state, the latter shown here to be controlled by activation of programmed cell death. The increasing evidence suggesting a dynamic nature of the $B$ cell mass includes an estimated average normal life time of B cells of $\sim 1-3$ mo (51) as well as a preliminary report demonstrating that B cell apoptosis is also involved in postpartum involuting islets (52). Likewise, resection of insulinomas rapidly induces $B$ cell regeneration and restoration of the $B$ cell mass and function in the remaining pancreas within a few days
$(3,5,6)$. It will be of importance to characterize the cell type in the remaining atrophic islet of insulinoma-transplanted rats possessing such a powerful proliferative potential as well as to characterize the nature of the activation of the apoptotic pathway.

The demonstration of the existence of an apoptotic pathway to regulate $\mathrm{B}$ cell mass in vivo is highly interesting with respect to a possible link to the pathogenesis of both non-insulindependent diabetes mellitus and insulin-dependent diabetes mellitus. Release of B cell proteins such as islet amyloid polypeptide (or amyloid fibrils which directly can trigger B cell apoptosis in vitro [53]) could represent part of the scenario observed late in non-insulin-dependent diabetes mellitus. Similarly, potential autoantigens such as glutamic acid decarboxylase $(54,55)$ could initially be released by apoptosis to subsequently prime the immune system in prediabetic insulin-dependent diabetes mellitus subjects. Moreover, cytokine treatment alone of islets in vitro initiates a similar apoptotic process (56).

Conclusion. The MSL-G-AN glucagonoma syndrome in rats is characterized by atrophic islets composed of densely packed resting A cells with retracted cytoplasm and small but apparently active B cells, surrounded by severely apoptotic, condensed exocrine tissue. Tumor-released glucagon and possibly GLP-1 may be candidates mediating this negative feedback loop. The MSL-G2-IN insulinoma syndrome is characterized by inactive $B$ cells, moderately reduced in size and undergoing programmed cell death. Tumor-induced hypoglycemia is a plausible candidate causing this phenomenon.

\section{Acknowledgments}

We thank Heidi I. Jensen, Erna E. Petersen, Kirsten Olesen, and Anna Magrethe Flarup for excellent technical help. We also wish to thank Drs. Erica Nishimura, J. S. Petersen, J. H. Nielsen, and J. Nerup for helpful discussions. Additionally, we are grateful to Dr. D. Drucker for providing information on his work on glucagonomas in nude mice before publication.

This work was supported in part by the Danish National Research Foundation (Center for Gene Regulation and Plasticity in the Neuroendocrine Network) and by The Danish Cancer Society. N. Blume received a fellowship from the Danish National Research Academy.

\section{References}

1. Drucker, D. J., Y. C. Lee, S. L. Asa, and P. L. Brubaker. 1992. Inhibition of pancreatic glucagon gene expression in mice bearing a subcutaneous glucagonproducing GLUTag transplantable tumor. Mol. Endocrinol. 6:2175-2184.

2. Ehrlich, P., D. Tucker, S. L. Asa, P. L. Brubaker, and D. J. Drucker. 1994. Inhibition of pancreatic proglucagon gene-expression in mice bearing subcutaneous endocrine tumors. Am. J. Physiol. 30:E662-E671

3. Chick, W. L., S. Warren, R. N. Chute, A. A. Like, V. Lauris, and K. C. Kitchen. 1977. A transplantable insulinoma in the rat. Proc. Natl. Acad. Sci. USA. 74:628-632.

4. O'Hare, M. M. T., C. Shaw, S. K. Swanston-Flatt, M. Marcelli, K. D. Buchanan, and P. R. Flatt. 1985. Influence of a transplantable insulinoma on the pancreatic status of insulin and pancreatic polypeptide in the rat. Diabetologia. 28:157-160.

5. Miyaura, C., L. Chen, M. Appel, T. Alam, L. Inman, S. D. Hughes, J. L. Milburn, R. H. Unger, and C. B. Newgard. 1991. Expression of reg/PSP, a pancreatic exocrine gene: relationship to changes in islet $\beta$-cell mass. Mol. Endocrinol. 5:226-234.

6. Chen, L., M. C. Appel, T. Alam, C. Miyaura, A. Sestak, J. O'Neil, R. H. Unger, and C. B. Newgard. 1992. Factors regulating islet regeneration in the postinsulinoma NEDH rat. In Pancreatic Islet Cell Regeneration and Growth. A. I. Vinik, editor. Plenum Press, New York. 71-80.

7. Madsen, O. D., L. C. Andersen, B. Michelsen, D. Owerbach, L.-I. Larsson, A. Lernmark, and D. F. Steiner. 1988. Tissue-specific expression of transfected 
human insulin genes in pluripotent clonal rat insulinoma lines induced during passage in vivo. Proc. Natl. Acad. Sci. USA. 85:6652-6656.

8. Madsen, O. D., C. Karlsen, E. Nielsen, K. Lund, H. Kofod, B. Welinder, J. F. Rehfeld, L.-I. Larsson, D. F. Steiner, J. J. Holst, and B. K. Michelsen 1993. The dissociation of tumor-induced weight loss from hypoglycemia in a transplantable pluripotent rat islet tumor results in the segregation of stable $\alpha$ and $\beta$-cell tumor phenotypes. Endocrinology. 133:2022-2030.

9. Madsen, O. D., C. Karlsen, N. Blume, H. Jensen, L.-I. Larsson, and J. Holst. 1995. Transplantable glucagonomas derived from pluripotent rat islet tumor tissue cause severe anorexia and adipsia. Scand. J. Clin. Lab. Invest. 55 (Suppl. 220):27-36.

10. Bhathena, S. J., G. A. Higgins, and L. Recant. 1981. Glucagonoma and glucagonoma syndrome. In Glucagon. Physiology, Pathophysiology and Morphology of the Pancreatic A-Cells. R. H. Unger and L. Orci, editors. Elsevier, New York. 413-438.

11. Geary, N., J. L. Sauter, and U. Noh. 1993. Glucagon acts in the liver to control spontaneous meal size in rats. Am. J. Physiol. 264:R116-R122.

12. Strubbe, J. H., J. G. Wolsink, A. M. Schutte, B. Balkan, and A. J. A Prins. 1989. Hepatic-portal and cardiac infusion of CCK-8 and glucagon induce different effects on feeding. Physiol. \& Behav. 46:643-646.

13. Geary, N. 1990. Pancreatic glucagon signals postprandial satiety. Neurosci. Biobehav. Rev. 14:323-338.

14. Sauter, J. L., and N. Geary. 1991. Hepatic portal glucagon infusions decrease spontaneous meal size in rats. Am. J. Physiol. 30:R154-R161.

15. Sauter, J. L., U. Noh, and N. Geary. 1991. Hepatic portal infusions of glucagon antibodies increases spontaneous meal size in rats. Am. J. Physiol 30:R162-R165.

16. Philippe, J. 1991. Structure and pancreatic expression of the insulin and glucagon genes. Endocr. Rev. 12:1-20.

17. Philippe, J. 1994. Pancreatic expression of the insulin and glucagon genes. Update 1994. Endocr. Rev. 2:21-27.

18. Ohlsson, H., K. Karlsson, and T. Edlund. 1993. IPF1, a homeodomaincontaining transactivator of the insulin gene. EMBO (Eur. Mol. Biol. Organ.) J. 12:4251-4259.

19. Leonard, J., B. Peers, T. Johnsson, K. Ferreri, S. Lee, and M. R. Montminy 1993. Characterization of somatostatin transactivating factor-1, a novel homeobox factor that stimulates somatostatin expression in pancreatic islet cells. Mol. Endocrinol. 7:1275-1283.

20. Jonsson, J., L. Carlsson, T. Edlund, and H. Edlund. 1994. Insulin-promoterfactor 1 is required for pancreas development in mice. Nature (Lond.). 371:606 609.

21. Petersen, H. V., P. Serup, J. Leonard, B. K. Michelsen, and O. D. Madsen 1994. Transcriptional regulation of the human insulin gene is dependent on the homeodomain protein STF1/IPF1 acting through the CT boxes. Proc. Natl. Acad. Sci. USA. 91:10465-10469.

22. Peers, B., J. Leonard, S. Sharma, G. Teitelman, and M. R. Montminy. 1994. Insulin expression in pancreatic islet cells relies on cooperative interactions between the helix loop helix factor E47 and the homeobox factor STF-1. Mol. Endocrinol. 8:1798-1806.

23. Serup, P., H. V. Petersen, E. E. Petersen, H. Edlund, J. Leonard, J. S. Petersen, L.-I. Larsson, and O. D. Madsen. 1995. The homeodomain protein IPF1/ STF1 is expressed in a subset of islet cells and promotes rat insulin 1 gene expression dependent on an intact E1 helix-loop-helix factor binding site. Biochem. $J$. In press.

24. Holst, J. 1983. Evidence that peak II GLI or enteroglucagon is identical to the C-terminal sequence (residues 33-69) of glicentin. Biochem. J. 207:381 388.

25. Ørskov, C., J. Jepesen, S. Madsbad, and J. Holst. 1991. Proglucagon products in plasma of non-insulin-dependent diabetics and nondiabetic controls in the fasting state and following oral glucose and intravenous arginine. J. Clin Invest. 87:415-423.

26. Madsen, O. D., L.-I. Larsson, J. F. Rehfeld, T. Schwartz, Å. Lernmark A. Labrecque, and D. F. Steiner. 1986. Cloned cell lines from a transplantable insulinoma are heterogeneous and express cholecystokinin in addition to islet hormones. J. Cell Biol. 103:2025-2034.

27. Blume, N., J. S. Petersen, L. C. Andersen, H. Kofod, T. Dyrberg, B. K. Michelsen, P. Serup, and O. D. Madsen. 1992. Immature transformed rat islet $\beta$ cells differentially express $\mathrm{C}$-peptides derived form the genes coding for insulin 1 and 2 as well as a transfected human insulin gene. Mol. Endocrinol. 6:299_ 307.

28. Larsson, L.-I., and D. M. Hougaard. 1993. Non-radioactive in situ mRNA hybridization using synthetic oligonucleotides: principles, combination with immunocytochemistry and quantitation. Neuroscience Protocols. 20:1-18.

29. Prooijen-Knegt, A. C. V., A. K. Raap, M. J. M. V. D. Burg, J. Vrolijk, and M. V. D. Ploeg. 1982. Spreading and staining of human metaphase chromosomes on aminoalkylsilane-treated glass slides. Histochem. J. 14:333-344.
30. Gavrieli, Y., Y. Sherman, and S. S. Ben. 1992. Identification of programmed cell death in situ via specific labeling of nuclear DNA fragmentation. J. Cell Biol. 119:493-501.

31. Gorzyca, W., J. Gong, and Z. Darzynkiewicz. 1993. Detection of DNA strand breaks in individual apoptotic cells by the in situ terminal deoxynucleotidyl transferase and nick translation assays. Cancer Res. 53:1945-1951.

32. Logothetopoulos, J., and J. M. Salter. 1960. Morphology and cytochemistry of alpha cells of the rabbit pancreas. Diabetes. 9:31-37.

33. Volk, B. W., and S. S. Lazarus. 1960. Studies on the diabetogenic action and the site of origin of glucagon. Diabetes. 9:53-62.

34. Logothetopoulos, J., B. B. Sharma, J. M. Salter, and C. H. Best. 1960. Glucagon and metaglucagon diabetes in rabbits. Diabetes. 9:278-285.

35. Lazarus, S. S., and B. W. Volk. 1958. The effect of protracted glucagon administration on blood glucose and on pancreatic morphology. Endocrinology. 63:359-371.

36. Petersson, B., and B. Hellman. 1963. Effects of long term administration of glucagon on the pancreatic tissue of rats and guinea pigs. Acta Endocrinol. 44:139-149.

37. Ørskov, C., J. J. Holst, and O. V. Nielsen. 1988. Effect of truncated glucagon-like peptide-1 [proglucagon-(78-107) amide] on endocrine secretion from pig pancreas, antrum, and nonantral stomach. Endocrinology. 123:2009_ 2013

38. Komatsu, R., T. Matsuyama, M. Namba, N. Watanabe, H. Itoh, N. Kono, and S. Tarui. 1989. Glucagonostatic and insulinotropic action of glucagonlike peptide I-(7-36)-amide. Diabetes. 38:902-905.

39. Kawai, K., S. Susuki, S. Ohashi, H. Mukai, H. Ohmori, Y. Murayama, and $\mathrm{K}$. Yamashita. 1989. Comparison of the effects of glucagon-like peptide-1(1-37) and - (7-37) and glucagon on islet hormone release from isolated perfused canine and rat pancreas. Endocrinology. 124:1768-1773.

40. Yamato, E., Y. Noma, Y. Tahara, H. Ikegami, Y. Yamamoto, T. Cha, H. Yoneda, T. Ogihara, C. Ohboshi, M. Hirota, and K. Shima. 1990. Suppression of synthesis and release of glucagon by glucagon-like peptide-1 (7-36 amide) without effect on mRNA level in isolated rat islets. Biochem. Biophys. Res. Commun 167:431-437.

41. Ørskov, C. 1992. Glucagon-like peptide-1, a new hormone of the enteroinsulinar axis. Diabetologia. 35:701-711.

42. Chen, L., I. Komiya, L. Inman, J. O'Neil, M. Appel, T. Alam, and R. H. Unger. 1989. Effects of hypoglycemia and prolonged fasting on insulin and glucagon gene expression. J. Clin. Invest. 84:711-714.

43. Kruszynska, Y. T., L. Villa-Komaroff, and P. A. Halban. 1988. Islet $\beta$ cell dysfunction and the time course of recovery following chronic over-insulinisation of normal rats. Diabetologia. 31:621-626.

44. Appel, M. C., and E. H. Kislauskis. 1984. Effects of glucose infusion in rats with a functional insulinoma. Diabetes. 33:82a. (Abstr.)

45. Appel, M. C. 1984. Effects of glucose on insulin gene expression. Diabeto logia. 27:252a. (Abstr)

46. Alam, T., L. Chen, A. Ogawa, J. D. Leffert, R. H. Unger, and K. L. Luskey. 1992. Coordinate regulation of amylin and insulin expression in response to hypoglycemia and fasting. Diabetes. 41:508-514.

47. Koranyi, L., D. E. James, E. W. Kraegen, and M. A. Permutt. 1992 Feedback inhibition of insulin gene expression by insulin. J. Clin. Invest. 89:432436.

48. Bursch, W., S. Paffe, B. Putz, G. Barthel, and R. Schultz-Hermann. 1990 Determination of the length of the histological stages of apoptosis in normal live and altered hepatic foci of rats. Carcinogenesis. 11:847-853.

49. Petersson, B., and B. Hellman. 1962. Long-term effects of restricted caloric intake on pancreatic islet tissue in obese-hyperglycemic mice. Metab. Clin. Exp. 11:342-348.

50. Bonner-Weir, S. 1994. Regulation of pancreatic $\beta$-cell mass in vivo. Recent Prog. Horm. Res. 49:91-104.

51. Finegood, D. T., L. Scaglia, and S. Bonner-Weir. 1995. Dynamics of $\beta$ cell mass in the growing rat pancreas. Diabetes. 44:249-256.

52. Scaglia, L., F. E. Smith, and S. Bonner-Weir. 1993. Programmed cell death in post-partum involuting islets. Diabetes. 42:11a. (Abstr.)

53. Lorenzo, A., B. Razzaboni, G. C. Weir, and B. A. Yankner. 1994. Pancreatic islet cell toxicity of amylin associated with type-2 diabetes mellitus. Nature (Lond.). 368:756-760.

54. Tisch, R., X.-D. Yang, S. M. Singer, R. S. Liblau, L. Fugger, and H. O. McDevitt. 1993. Immune response to glutamic acid decarboxylase correlates with insulitis in non-obese diabetic mice. Nature (Lond.). 366:72-75.

55. Kaufman, D. L., M. Clare-Salzler, J. Tian, T. Forsthuber, G. S. Ting, P Robinson, M. A. Atkinson, E. E. Sercarz, A. J. Tobin, and P. V. Lehmann. 1993. Spontaneous loss of T-cell tolerance to glutamic acid decarboxylase in murine insulin-dependent diabetes. Nature (Lond.). 366:69-72.

56. Rabinovitch, A., P. W. Suarez, Y. Shi, A. R. Morgan, and R. C. Bleackley 1994. DNA fragmentation is an early event in cytokine-induced islet beta-cell destruction. Diabetologia. 37:733-738. 